\title{
Experimental Investigation of Performance, Combustion and Emission Characteristics of Palash Biodiesel on Diesel Engine
}

\author{
Maloth Ramulunaik*, P. Bridjesh and D. Mallesham \\ Department of Mechanical Engineering, MLR Institute of Technology, \\ Hyderabad - 500043, Telangana, India; malothramunaik16@gmail.com, \\ meetbridjesh@gmail.com, dandumallesham14@gmail.com
}

\begin{abstract}
Backgrounds/Objective: To investigate the combustion performance and emissions characteristics of blends of Palash biodiesel on VCR diesel. Method/statistical Analysis: Blends of palash biodiesel and diesel as a fuel was used in VCR diesel engine at different loads. The variations on the performance parameters like Brake Thermal Efficiency (BTE), Brake Specific Fuel Consumption (BSFC), emissions parameters like Carbon Monoxide (CO), Hydro Carbon (HC), Nitrogen Oxides (NOx), and combustion parameters like heat release rate (HRR) and cylinder pressure are analyzed and compared with that of diesel. Finding: The results revealed that engine performance was better for B20 blend of palash biodiesel. BSFC decreased and BTE has increased when compared to that of diesel. $\mathrm{HC}$ and $\mathrm{CO}$ emissions have found decreased with blends of palash biodiesel and NOx emission has increased as compared with that of diesel. Improvement: By the use of biodiesel engine exhaust emissions can be reduced.
\end{abstract}

Keywords:Blends of Palash biodiesel, Diesel, Engine Performance, Exhaust Emission and Combustion Performance, VCR Engine

\section{Introduction}

Fossil fuels (petrol and diesel etc.) used in IC engine release harmful gases, impacting environment and health. Biodiesel acts as an alternative to petroleum based fuels. Biodiesel has similar physiochemical properties and it is a renewable resource. Researchers suggested that biodiesel produce nearly a same power yield but somewhat lower heat efficiency when compared with diesel. The IC engines don't need to change geometrically for biodiesel oil. The use of bio-diesel increases the lifespan of the IC engine.

In ${ }^{1}$ studied that emissions decreased at different loads for both the blends compared with diesel fuel while NOx exhaust is seen to be higher. $\mathrm{In}^{2}$ revealed that BTE of oleander oil methyl esters is found higher and BSFC lower when compared to that of kusum and groundnut oil methyl esters. Groundnut oil methyl esters show less exhaust compared to oleander and kusum oil methyl esters.

$\mathrm{In}^{3}$ showed less exhaust and higher performance for B20 than various blends and pure diesel. The BTE is higher than diesel and gases exhaust were $24 \%, 7.9 \%$, and $21 \%$ lesser than that of pure diesel.

$\operatorname{In}^{4}$ recorded improved fuel properties and lower exhaust of $\mathrm{HC}$ and $\mathrm{CO}$ and yet high amount of NOx.

$\mathrm{In}^{\underline{5}}$ affirmed BTE of biodiesel blends was more than that of diesel. The emission of smoke, HC and NOx of biodiesel blends were more than that of diesel alone. Be that as it may, the exhaust temperature for biodiesel blends was not much as diesel. 
$\mathrm{In}^{\underline{6}}$ showed the effect of Variable Compression Ratio (VCR) on an engine controlled with waste cooking oil produced biodiesel and diesel. From this outcomes affirmed that VCR are 14 to 18 achieved, $18.39 \%, 27.48 \%$, $18.5 \%$, and $19.82 \%$ increments in BTE if there ought to emerge an experiment of biodiesel blends. On a normal, the $\mathrm{CO}_{2}$ increments by $15.12 \%$, the HC surge decreased by $48 \%$, CO outcomes are decreased by $36.1 \%$ and $\mathrm{NOx}$ fumes expanded by $36.2 \%$ when Compression Ratio (CR) was increased from 15 to 18 .

$\mathrm{In}^{7}$ showedthat the BSFC, BTE and NOx increase and the emission of $\mathrm{CO}$ and $\mathrm{HC}$ decrease with an increasing karanja biodiesel blends.

$\mathrm{In}^{\underline{8}}$ showed that $\mathrm{CO}$ and $\mathrm{HC}$ decreased and NOx increased with an increasing Compression Ratio (CR). BTE and BSFC were also increasing with an increasing CR of Waste Fried Oil Methyl Ester (WFOME) blends.

In this experimental investigation, the performance and emission characteristics of blends of palash biodiesel are analyzed on diesel engine at different loads and at constant speed.

\section{Materials and Methods}

The palash biodiesel mixed with pure diesel and it was utilized in the IC engine. The properties of blends of biodiesel and engine specifications are presented in Table 1. The experiment incorporated pure diesel (100\%diesel), B10 (10\% of palash biodiesel $+90 \%$ of pure diesel), B20 ( $20 \%$ of palash biodiesel $+80 \%$ of pure diesel), B30 (30\% of palash biodiesel $+70 \%$ of pure diesel).

\subsection{Experimental set-up}

In this experiment a $3.5 \mathrm{kw}$ diesel engine, kirloskar make was used. This engine connected with DC electrical dynamometer. AVL 5G analyzer was used to measure the engine exhaust composition and AVL 437 Smoke meter was used to measure the smoke opacity. Schematic diagram of the experimental setup is shown in Figure 1.

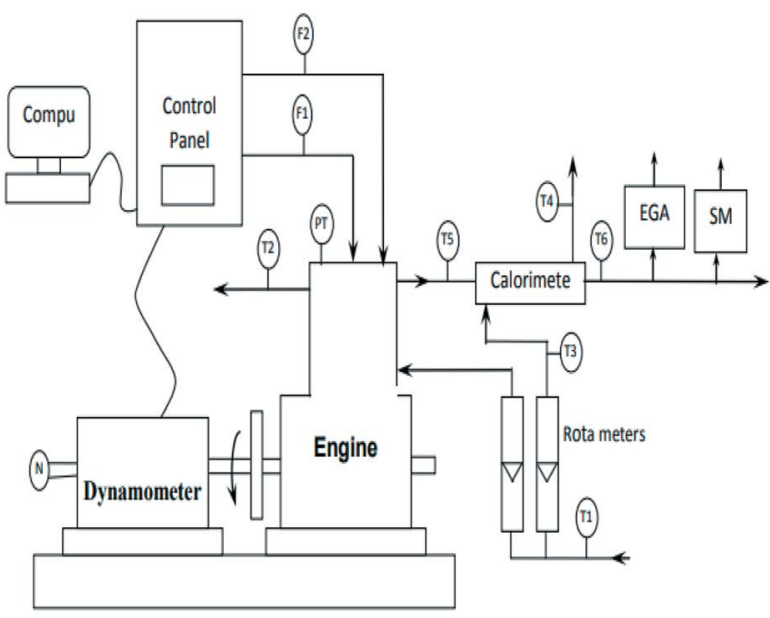

Figure 1. Line diagram of experimental setup.

\subsection{Test Program}

The investigation is on palash biodiesel blends and compared with diesel for variable loads like $0,2,4,6,8,10$, $12(\mathrm{~kg})$ and its having horse power $3.50 \mathrm{~kW} @ 1500 \mathrm{rpm}$ at the compression ratio 18 . Also checked for circulation cooling water and lubricant oil level in the engine. Three

Table 1. Physio-chemical properties of blends and diesel

\begin{tabular}{|c|c|c|c|c|c|c|}
\hline Property & Units & B 10 & B 20 & B 30 & Diesel & ASTM Standard \\
\hline VISCOSITY@ @40C & CST & 1.773 & 1.9 & 2.04 & 2.12 & ASTM D 445 \\
\hline PH VALUE & - & 5.28 & 5.5 & 5.63 & - & - \\
\hline CLOUD POINT & $0 \mathrm{C}$ & -8 & -8 & -8 & - & ASTM D 2500 \\
\hline POUR POINT & $0 \mathrm{C}$ & -21 & -21 & -21 & - & ASTM D 97 \\
\hline CARBON RESIDUE & $\%$ & 0.005 & 0.009 & 0.012 & - & ASTM D 189 \\
\hline DENSITY & $\mathrm{Kg} / \mathrm{L}$ & 0.87 & 0.884 & 0.889 & 0.828 & ASTM D 1298 \\
\hline ACIDIC VALUE & $\mathrm{mgKoH} / \mathrm{gm}$ & 0.19 & 0.189 & 0.1973 & - & ASTM D 664 \\
\hline FREE FATTY ACID & $\mathrm{mgKoH} / \mathrm{gm}$ & Nil & $\mathrm{NiL}$ & Nil & - & ASTM D 5555 \\
\hline CETANE VALUE & - & 47 & 48 & 49 & 51 & ASTM D 613 \\
\hline CALORIFIC VALUE & $\mathrm{KJ} / \mathrm{KG}$ & 40840 & 40150 & 39790 & 42000 & ASTM D 5865 \\
\hline FLASH POINT & $0 \mathrm{C}$ & 127 & 134 & 141 & 66 & ASTM D 92 \\
\hline FIRE POINT & 0C & 172 & 180 & 185 & - & ASTM D 92 \\
\hline
\end{tabular}


blends of palash blends are B10, B20, B30 and diesel fuel are utilized in this experiment. The engine was sufficiently heated up and off set before taking everything about readings. The introduction parameters included BSFC, BTE, Exhaust Gas Temperature (EGT), CO, UHC, NOx, cylinder pressure and HRR as shown in Table 2.

Table 2. Test engine and instrument details

\begin{tabular}{|l|l|}
\hline \multicolumn{1}{|c|}{ General details } & \multicolumn{1}{|c|}{4 stroke 3.5 kw @ 1500rpm } \\
\hline Bore & $87.50 \mathrm{~mm}$ \\
\hline Stroke & $110.00 \mathrm{~mm}$ \\
\hline Compression ratio & $12: 1-18: 1$ \\
\hline Ignition & Compression ignition \\
\hline Temperature sensor & Type $-\mathrm{k}$ cromel \\
\hline Starting & Self starting motor \\
\hline Cooling & Water \\
\hline Dynamometer & Dc electric dynamometer \\
\hline Smoke meter & AVL 437 smoke meter \\
\hline Exhaust gas analyzer & AVL 444 G analyzer \\
\hline
\end{tabular}

\section{Results and Discussion}

\subsection{Engine Performance}

\subsubsection{Brake Specific Fuel Consumption (BSFC)}

Figure 2 shows the BSFC of diesel engine with blends of palash biodiesel and diesel fuel. For all blends of palash biodiesel, BSFC is less than diesel fuel. As theload increases, theBSFC decreases. At $100 \%$ load, the BSFC of $\mathrm{B} 10, \mathrm{~B} 20, \mathrm{~B} 30$ showed $3.2 \%, 6.45 \%, 3.2 \%$ decrease

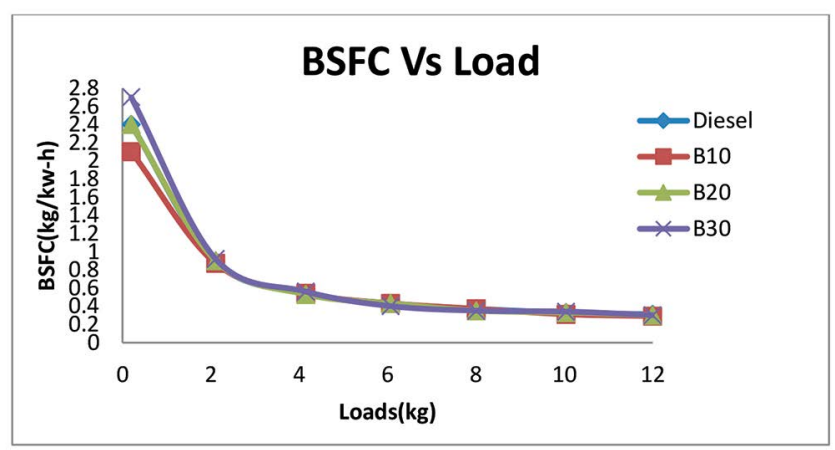

Figure 2. Variations of BSFC at loads. compared to diesel fuel. It is due to high viscosity blends of palash biodiesel.

\subsubsection{Brake Thermal Efficiency (BTE)}

Figure 3 shows the various BTE comparing with diesel and palash blends at various loads. At 100\% load, BTE for diesel, B10, B20, and B30 are observed as $27.89 \%$, $30.31 \%, 30.33 \%$, and $30.31 \%$ respectively. As the viscosity of palash blends is higher than diesel, there is decline in atomization and vaporization of which results in higher fuel utilization and lower BTE compare with palash blends. It was seen that at $100 \%$ load, BTE changed to $8.67 \%, 8.74 \%, 8.67 \%$ of $\mathrm{B} 10, \mathrm{~B} 20$ and $\mathrm{B} 30$ individually when compare to that of diesel. The BTE is increasingly affected by the calorific value of the test fuels.

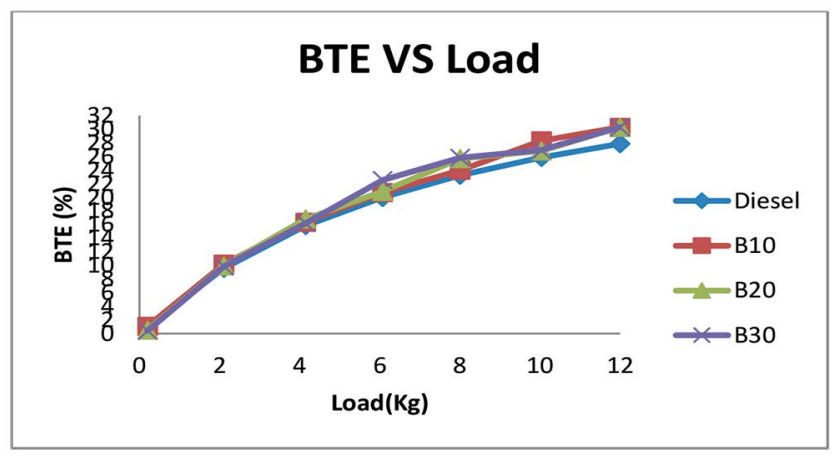

Figure 3. Variations of BTE at loads.

\subsection{Emission Characteristics}

\subsubsection{Exhaust Smoke}

Figure 4 shows the at $100 \%$ load, the smoke intensity for B10, B20, B30 fuels are higher compared to diesel. The smoke opacity of diesel and B10, B20, B30 are 98.55 and 96.5, 95.098 .4 respectively. It was observed that at high load, smoke opacity changed to $2.03 \%, 3.55 \%$, and $0.10 \%$ of B10, B20, and B30 when compared with that of diesel.

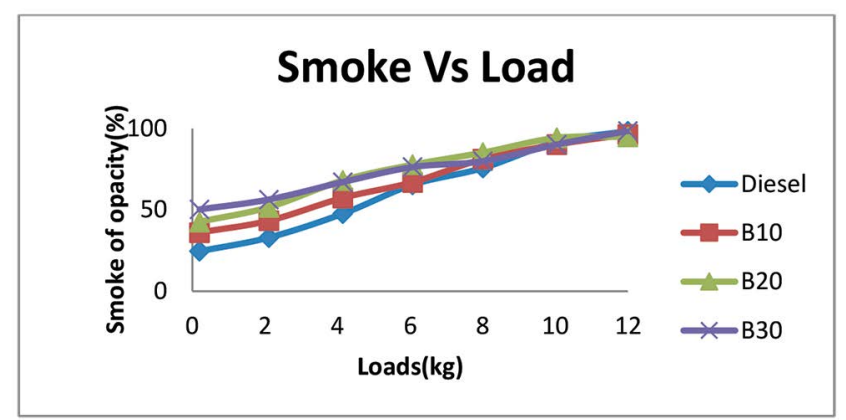

Figure 4. Variations smoke of opacityat loads. 
This might be because of poor atomization and of high viscosity and low volatility of palash biodiesel blends, resulting in higher smoke emission at 100\% load.

\subsubsection{Nitrogen Oxides (NOx)}

Figure 5 shows the results at $100 \%$ load, NOx for diesel, B10, B20,and B30 as observed to be 768,730, 523, $487 \mathrm{ppm}$ respectively. It was observed that at $100 \%$ load, NOx decreased to $4.94 \%, 31.9 \%, 36.58 \%$ of B10, B20 and $\mathrm{B} 30$ respectively when compared to that of diesel. When the loads are increased, the NOx is increasing. It seems that, the most part of nitrogen does not react with oxygen in the ignition chamber. In any case high temperatures in the chambers cause the nitrogen to react with oxygen and produce NOx emission.

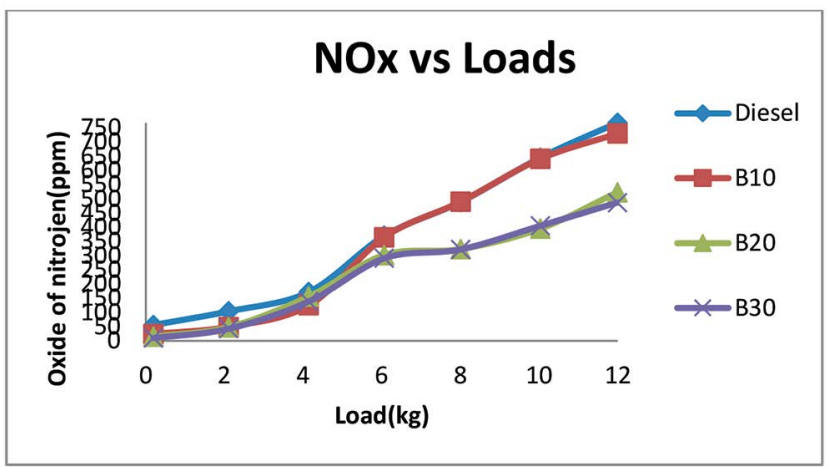

Figure 5. Variations of NOx at loads.

\subsubsection{Unburned Hydro Carbons (UHC)}

Figure 6 shows the UHC emission for palash biodiesel blends $\mathrm{B} 10, \mathrm{~B} 20, \mathrm{~B} 30$ are $20 \%, 6.6 \%, 26.6 \%$ respectively. The HC emission is formed because of Non-Homogeneous of fuel air mixture. Due to this non-homogeneity some lower forms in combustion chamber will be too lean to combust properly and other some may be too rich with

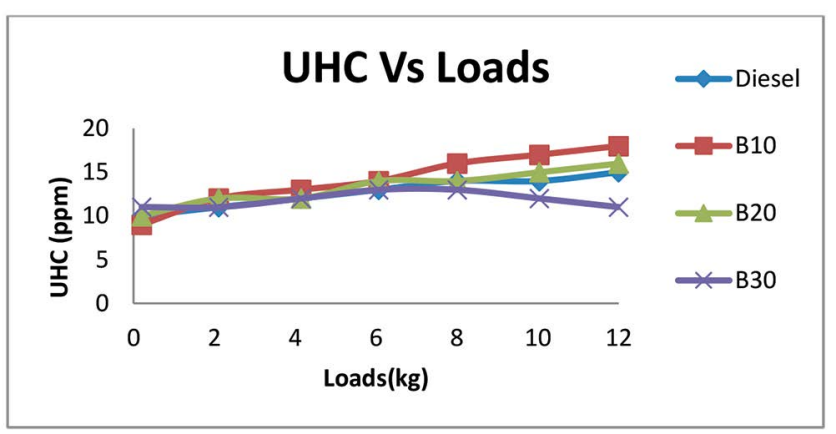

Figure 6. Variations of UHC at loads. most enough to burn all the fuel. For palash biodiesel blend B20 the HC emission was lower compared to diesel because of more oxygen present in B20.

\subsubsection{Carbon Monoxide (CO)}

The CO emission of palash biodiesel blends B10, $\mathrm{B} 20$ and $\mathrm{B} 30$ are $26.2 \%, 12.8 \%, 33.3 \%$ respectively as compared to diesel (Figure 7). For B20, CO emission is low because of more oxygen present in B20 led to complete combustion.

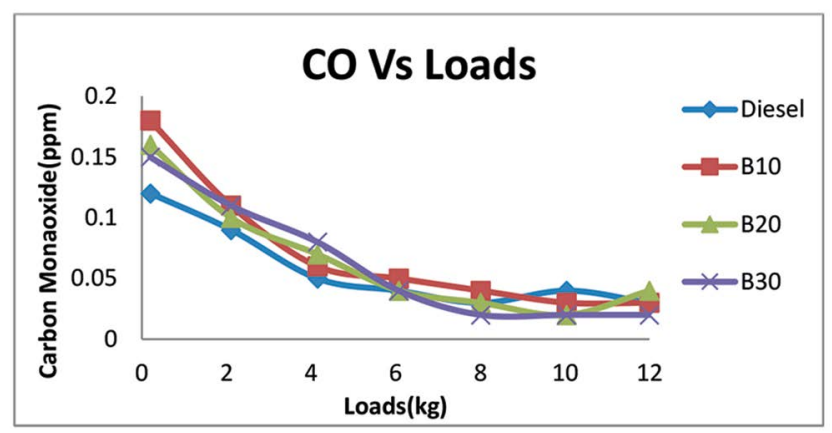

Figure 7. Variations of Carbon Mona oxide at loads.

\subsection{Combustion Characteristics}

\subsubsection{Cylinder Pressure vs Crank Angle@100\% Load}

Figure 8 shows the cylinder pressure as a factor of crank angle and applied at $100 \%$ load. When we start the IC diesel engine, at the beginning the combustion of the cylinder pressure goes to the peak level because high amount of fuel is consumed at the beginning of the combustion and released high amount of heat. The peak level pressure of diesel observed as 23.8 bar at zero load, 32.3 bar at $2 \mathrm{~kg}$, $52.2 \mathrm{bar}$ at $6 \mathrm{~kg}$ and $64.1 \mathrm{bar}$ at $12 \mathrm{~kg}(100 \%$ load $)$. At a

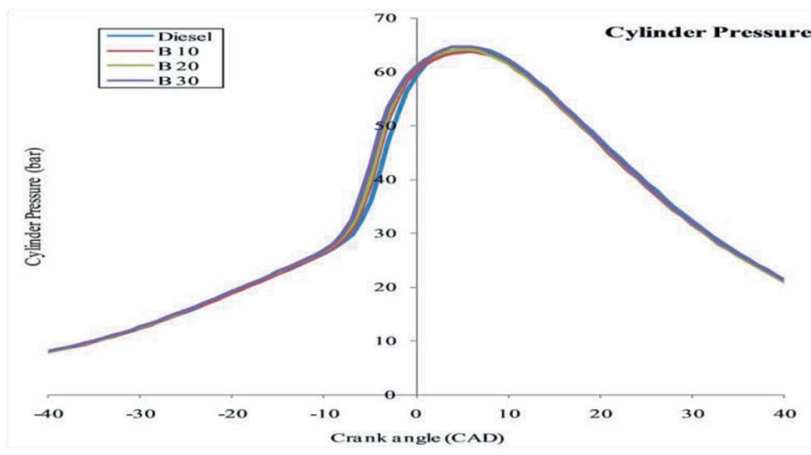

Figure 8. Cylinder pressure vs Crank angle @ 100\% load. 
crank angle $5 @ 100 \%$ load, the cylinder pressure observed as 64.01 bar for diesel, 63.03 for B10, 63.9 for B20 and 64 for B30. The cylinder pressure of diesel is higher than that of blends of palash biodiesel because of high viscosity and poor volatility.

\subsubsection{Heat Release Rate (HRR)}

Figure 9 shows the HRR as a factor of crank angle and applied at $100 \%$ load. When we start the IC diesel engine, the cylinder pressure goes to the peak level because of high amount of fuel consumed and also high amount of heat released at the beginning of the combustion. It was observed that when the load is increased the fuel consumptions and HRR are also increased. The peak level HRR was observed as 49.7J/deg for diesel, 54.37J/deg for $\mathrm{B} 10,52.6 \mathrm{~J} / \mathrm{deg}$ for B20,53.27J/deg for B30 respectively at 5 degree of crank angle ignition starts. The HRR curve exhibited drop due to change in cooling effect that occurs shortly after onset of the ignition.

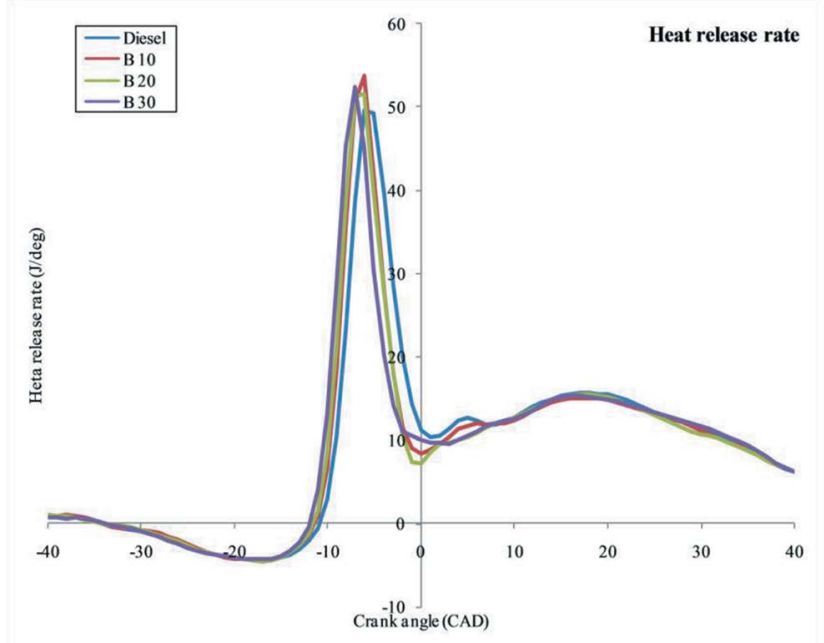

Figure 9. Heat release rate vs Crank angle @ 100\% load.

\section{Conclusion}

Given below are the conclusions drawn from this investigation:

- When the blends of palash biodiesel are used on diesel, the Engine runs very smoothly.

- At $100 \%$ load, Brake Thermal Efficiency (BTE) of palash biodiesel blend B20 is found optimal and 2.44\% higher than diesel.
- At $100 \%$ load, Brake Specific Fuel Consumption (BSFC) of palash biodiesel blend B20 is lower than others (blends B10, B30 and diesel).

- At $100 \%$ load, the exhaust smoke of palash biodiesel blend B20 is more than that of B10, B30 and diesel.

- At $100 \%$ load, the exhaust NOx of palash biodiesel blend B20 is very lower than B10, B30 and diesel.

- At $100 \%$ load, the exhaust Hydro Carbon (HC) of palash biodiesel blend B30 is lower than B10, B20 and Diesel.

- At $100 \%$ load, the exhaust carbon monoxide (CO) of palash biodiesel blend B30 is less than Diesel. Carbon monoxide (CO) of B10 is equal to Diesel. But carbon monoxide (CO) of B20 is $33.3 \%$ more than Diesel.

- At $100 \%$ load, Cylinder pressure of palash biodiesel blend B20 is slightly lesser than Diesel but more than $\mathrm{B} 10$ and B30.

- At $100 \%$ load, Heat release rate (HRR) of palash biodiesel blend B20 is 5.83\% more than Diesel but lesser than B10, B30 blends.

\section{References}

1. Kathirvelu B, Subramanian S, Govindan N, Santhanam S. Discharge attributes of biodiesel got from jatropha seeds and fish squanders in a diesel engine. Manageable Environment Research. 2017; 27(6):283-90. https://doi. org/10.1016/j.serj.2017.06.004

2. Nair JN, Kaviti AK, Daram AK. Analysis of execution and discharge on pressure start engine fuelled with mixes of Neem biodiesel. Egyptian Journal of Petroleum. 2017; 26(4): 927-31. https://doi.org/10.1016/j.ejpe.2016.09.005

3. Yadav AK, Khan ME, Dubey AM, Pal A. Execution and emanation attributes of a transportation diesel motor worked with non-consumable vegetable oils biodiesel. Contextual Analyses in Thermal Engineering. 2016; 8:23644. https://doi.org/10.1016/j.csite.2016.08.001

4. Ali H, Mashud M, Rubel R, Ahmad RH. Biodiesel from neem oil as an alternative fuel for diesel engine. Procedia Engineering. 2013; 56:625-30. https://doi.org/10.1016/j. proeng.2013.03.169

5. Srithar K, Arun Balasubramanian K, Pavendan V, Ashok Kumar B. Experimental test on blending of two biodiesels mixed with diesel as elective fuel for diesel engine. Diary of King Saud University-Engineering Sciences. 2017; 29(1):50-6. https://doi.org/10.1016/j.jksues.2014.04.008 
6. EL Kasaby M, Nemit-allah MA. Studying the effect of compression ratio on an engine fuelled with waste cooking oil produced biodiesel/diesel fuel. Alexandria engineering Journal. 2014; 52:1-11. https://doi.org/10.1016/j. aej.2012.11.007

7. Gangil S, Priyanka R. Investigation of engine performance and emission with methyl ester of karanja oil. Perspective in science. 2016; 8:241-43. https://doi.org/10.1016/j. pisc.2016.04.040

8. Hirkude J, Padalkar AS. Experimental Investigation of compression ratio on performance and emissions of CI engine operated with waste fried oil methyl ester blend. Fuel Processing Technology. 2014; 128:367-75. https://doi. org/10.1016/j.fuproc.2014.07.026 